\title{
The vase life of waxflower (Chamelaucium Desf.) is affected by the weight ratio of flowers to stem
}

\author{
Cao D. Dung ${ }^{1 *}$, Kevin Seaton ${ }^{2}$,Zora Singh ${ }^{3}$ \\ ${ }^{1}$ Potato, Vegetable and Flower Research Center \\ Thai phien village, Ward 12, Da Lat, Lam Dong, Vietnam \\ ${ }^{2}$ Department of Agriculture and Food Western Australia \\ 3 Baron-Hay Court, South Perth, WA 6151, Australia \\ ${ }^{3}$ Department of Environment and Agriculture \\ Curtin University \\ Kent St., Bentley, Perth, WA 6102, Australia
}

\begin{abstract}
The effect of flower weight on changes in the vase life of flowers and leaves of waxflowers was studied by evaluating the arranged flower weight of cultivars derived from the Chamelaucium uncinatum, Chamelaucium megalopetalum and Verticordia species. Competition for water and carbohydrates between flowers and leaves influenced vase life. The removal of flowers had at least four times the effect on leaf vase life as the removal of leaves on flower vase life. Supplying exogenous sucrose to satisfy the demand for carbohydrates negated this effect, indicating that flowers depend on carbohydrates being supplied from leaves to maintain vase life. Cultivars with a greater proportion of flowers (on a weight basis) improved the vase life of flowers at the expense of the leaves. Cultivars with large flowers or many small flowers or a greater weight ratio of flowers to stem appeared to draw more carbohydrates and water from the leaves, giving them a longer vase life and decreasing the vase life of the leaves. The vase life of flowers increased with the stage of opening of flowers up to $50 \%$ opening and then decreased up to $100 \%$ opening.
\end{abstract}

Key words: carbon hydrate, flower weight, leaves, sources and sinks, vase life, waxflowers, water competition

\section{INTRODUCTION}

Competition between flowers and leaves for carbohydrates and water may change the vase life of flowers and leaves, as occurred for Protea neriifolia, where flowers drew carbohydrates from leaves and consequently decreased the vase life of leaves (Dail and Paull 1995). The leaves of 'Crimson Yu-lo' Grevillea also competed with the flowers for water, resulting in a decrease in the vase life of the inflorescence ( $\mathrm{He}$ et al. 2006). The removal of flower, fruit, or vegetative buds is a common treatment to simulate sink limitation (Turner et al. 2012, Murphy et al. 2005).

Flowers are a significant sink for carbohydrates, deriving them from leaves where sucrose is hydrolysed and the resulting glucose and fructose are transported to the flower buds (Paulin 1981, Marissen and La Brijn 1995). The removal of cut rose leaves led to a decrease in carbohydrate concentration in flower buds and the removal of the corolla resulted in an increase in carbohydrate level in leaves (Marissen and La Brijn 1995). Similarly, the removal of inflorescence of cut Protea neriifolia

\footnotetext{
*Corresponding author. 
delayed the onset of leaf blackening and increased the levels of starch and carbohydrates in leaves (Dail and Paull 1995). The removal of flowers of 'Forever Yours' cut rose and 'White Sim' cut carnation reduced water uptake by $20.4 \%$ and $27.1 \%$, respectively; however, the removal of leaves from those cut flowers decreased water uptake by $78.5 \%$ and $37.3 \%$, respectively (Carpenter and Rasmussen 1974).

The reduction of the longevity of cut flowers in vases is often caused by water stress (van Doorn 1997). The presence of leaves on stems resulted in a greater loss of water in the inflorescence of Grevillea 'Crimson Yu-lo' and consequently decreased the vase life of the inflorescence. The vase life of Grevillea 'Crimson Yu-lo' flowers on cut stems with four or six leaves was significantly shorter when compared to the vase life of flowers with zero or two leaves per stem (He et al. 2006). The leaves of Chamelaucium uncinatum 'Purple Pride' and 'Alba' had higher turgor and lower osmotic potential than the flowers, resulting in a greater decrease in the water potential of the leaves compared to the flowers. Increased water balance led to an increase in the vase life of the leaves of cultivars of C. uncinatum (Joyce and Jones 1992).

The increased vase life of $C$. uncinatum 'Alba' and 'Purple Pride' with exogenously applied sucrose, abscisic acid and/or $\mathrm{KCl}$ was mainly due to improved water uptake and water balance (Joyce and Jones 1992). Vase life was further improved by also adding an antibacterial chemical (Joyce 1988, Joyce and Jones 1992). In conclusion, leaves are a source of carbohydrates for cutflowers, contributing to extend vase life, whilst evapotranspiration from the leaf surface leads to decreased water balance, causing water stress in the stems and therefore shortens the vase life of cut flowers. The aim of this study was to determine the relationship between sources and sinks as well as the effect of changes in the weight of flowers on changes in the vase life of flowers and leaves of several cultivars.

\section{MATERIAL AND METHODS}

\section{Plant materials}

Cultivars of C. uncinatum - 'Purple Pride', 'Micro wax', 'Dancing Queen' and 'WX69', Verticordia $\times$ C. uncinatum - 'Southern Stars', 'WX73' and 'WX35' and C. megalopetalum hybrids - 'Laura Mae Pearl' and 'WX87' were cultivated using irrigation and fertigation at the Medina Research Station (32 $\left.{ }^{\circ} 13^{\prime} 18^{\prime \prime} \mathrm{S}, 115^{\circ} 38^{\prime} 50^{\prime \prime} \mathrm{E}\right)$ of the Department of Agriculture and Food Western Australia (DAFWA) (Seaton and Poulish 2010). Flowering stems of approximately 50\% flower opens were harvested from an average of five 5 -year-old bushes in the early morning, from July through November, and the cut ends of stems were immediately placed upright in buckets of deionised water in the field, and then transported to the laboratory of DAFWA at South Perth, taking about 35 minutes, by airconditioned vehicle at approximately $20^{\circ} \mathrm{C}$. At the laboratory, flowering stems were then chosen with a similar of number of flowers and branches, and recut with secateurs in deionised water to $30 \mathrm{~cm}$ in length (from the cut ends to the most extreme opened-flowers) for each treatment (Seaton and Joyce 1996, Seaton et al. 2010).

\section{Experimental design and treatments}

Experiment 1. Effect of the removal of flowers or leaves on the vase life of different cultivars

Cut stems of 'Purple Pride', 'Micro wax', 'Dancing Queen', 'WX69', 'Southern Stars', 'WX73', 'WX35' and 'Laura Mae Pearl' were subject to the following treatments: (i) intact stems, (ii) all leaves removed from stems and (iii) all flowers and buds removed from stems. The stems were placed in vases of either deionized (DI) water or $29.2 \mathrm{mmol}$ sucrose and $100 \mathrm{mg} \mathrm{L}^{-1} \mathrm{HQS}$ for vase life comparison.

Experiment 2. Effect of changes in the weight ratio of flowers to stem on changes in the vase life ratio of flowers to leaves

$30 \mathrm{~cm}$ flowering stems of 'Purple Pride', 'Micro wax', 'Dancing Queen', 'WX69', 'Southern Stars', 'WX73', 'WX35' and 'Laura Mae Pearl' with different flower weights and densities to give a range of weight ratios of flowers to stems were selected for the study. The weight ratio of flowers to stem was determined by weighting whole stems and flowers. Cut stems of cultivars were either placed in DI water or $10 \mathrm{~g} \mathrm{~L}^{-1}(29.2 \mathrm{mmol})$ sucrose and $100 \mathrm{mg} \mathrm{L}^{-1} \mathrm{HQS}$ for vase life assessment and the vase life ratio of flowers to leaves was determined. An average weight of eight stem ratio or vase life ratio value was determined. There were eight replicates for each vase life treatment.

Experiment 3. The effect of changes in weight ratio of flowers to stem of ' $W X 87$ ' through different flowering stages on the changes in vase life ratio of flowers to leaves

Cut stems of 'WX87' at 25, 50 and 100\% flower opening stages (Tab. 1) were harvested during 
Table 1. Stages of opening of flowers of 'WX 87'

\begin{tabular}{lc}
\hline Stage & Degree of opening $(\%)$ \\
\hline 1 & 25 \\
2 & 50 \\
3 & 100 \\
\hline
\end{tabular}

September. An opened flower was determined when the entire receptacle and anthers were visible (Seaton, pers. com.) (Fig. 1). The weight of flowers and whole stems of $30 \mathrm{~cm}$ flowering stems were weighted eight times. The weight ratio of flowers to stem was determined as the weight of flowers over the whole stem and averaged for eight stems. Vase life in DI water alone or $10 \mathrm{~g} \mathrm{~L}^{-1}(29.2 \mathrm{mmol})$ sucrose plus $100 \mathrm{mg} \mathrm{L}^{-1} \mathrm{HQS}$ for eight cutting stems at each flowering stage was recorded and the vase life ratio of flowers to leaves was determined and an average vase life ratio value was determined for eight stems.

All experimental vase life assessments were conducted in a vase room maintained at 20 $\pm 2{ }^{\circ} \mathrm{C}, 60 \pm 10 \%$ relative humidity with a $12 \mathrm{~h}$ photoperiod. The light flux densities are $8 \mu \mathrm{mol}$ $\mathrm{m}^{-2} \mathrm{~s}^{-2}$. In each treatment, individual stems were placed in a $250 \mathrm{ml}$ vase containing vase solution treatments. The experiments were arranged in a completely randomized design and each treatment was repeated eight times.

\section{Measurements}

\section{Vase life and flower drop}

The vase life of flowers was determined when $50 \%$ or more of opened flowers had closed or showed damage. For genotypes, where flowers dropped before closing, the end of vase life was determined when more than $50 \%$ of opened flowers had dropped. The vase life of leaves was determined when more than $50 \%$ of the leaves were fully desiccated or yellow for their full length.

\section{Organ measurement}

Eight flowering stems were recut under water to $30 \mathrm{~cm}$ in length (measured from the cut end to the furthest open flower) and the surface water on the leaves and flowers was then blotted dry with tissue paper. Flowers, buds, leaves and stems of cut stems were weighted with an electronic scale in an airconditioned room at $20 \pm 2^{\circ} \mathrm{C}, 60 \pm 10 \%$ relative humidity.

\section{Weight ratio of flowers to stem}

The weight ratio of flowers to stems was determined as the weight of flowers over the weight of stem, leaves and flowers.

\section{Vase life ratio of flowers to leaves}

The vase life ratio of flower to leaf was determined as flower vase life over leaf vase life.

\section{Vase solution preparation}

Vase solutions were prepared by dissolving $10 \mathrm{~g}$ of sucrose and $100 \mathrm{mg}$ HQS into $1 \mathrm{~L}$ of deionized water to make a vase solution of $29.2 \mathrm{mmol}$ sucrose and $100 \mathrm{mg} \mathrm{L}^{-1} \mathrm{HQS}$.

\section{Data analysis}

The vase life of flowers and leaves from treatment effects were analysed by 1-way ANOVA using the statistical package Genstat XV (Lawes Agricultural Trust, Rothamsted Experimental Station, UK). Replication was eight folds consisting of a single stem in individual vases. Treatment means were compared by LSD at $p<0.05$ and standard errors of the mean $( \pm \mathrm{SE})$ are shown as appropriate. The correlation coefficient between flower to leaf vase life ratio and the weight ratio of flowers to stem was analysed with the statistical package Genstat

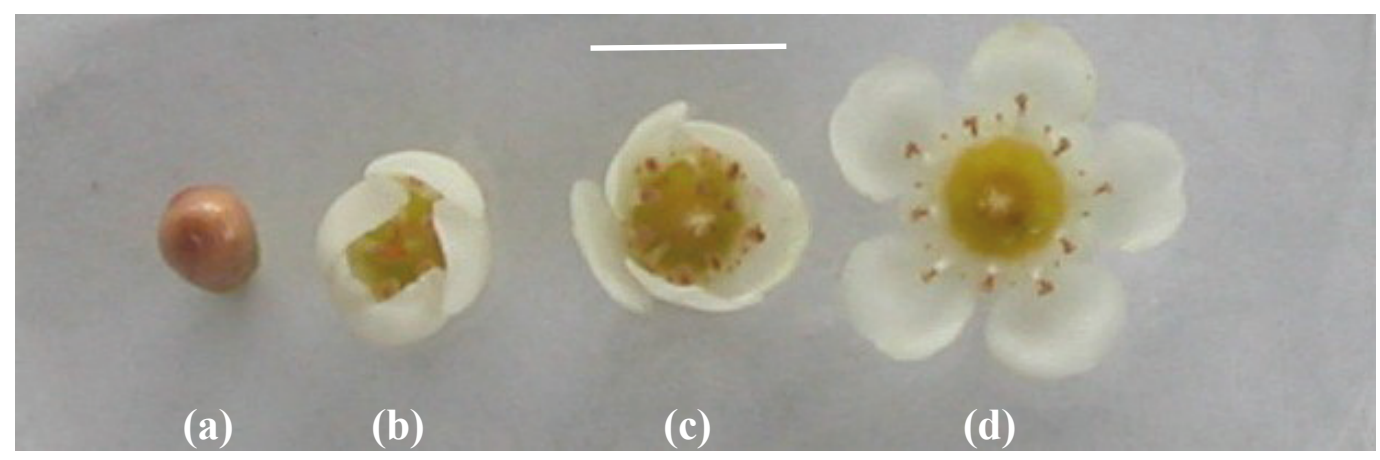

Figure 1. Determination of an opened flower of 'WX87': bud (a), partially opened flower (b), open flower (c), and fully opened flower (d). Horizontal scale bar represents $1 \mathrm{~cm}$ 
XV by using the simple linear model or polynomial regression.

\section{RESULTS}

Effect of removal of leaves or flowers on vase life of waxflowers

The removal of leaves significantly $(p<0.05)$ increased the vase life of flowers of all cultivars in DI water by an average of 4.8 days or $30 \%$ while the removal of flowers significantly $(p<0.05)$ increased vase life of the leaves of all cultivars by an average of 21.7 days or $117.5 \%$ compared to intact stems (Figs 2 a and 2 b). The addition of sucrose reversed the gain in vase life from the removal of leaves for most (six out of eight) cultivars (Fig. 2 a), with a decrease in vase life of 2.2 days or $8.2 \%$. The removal of the flowers of stems held in a sucrose vase solution increased the vase life of leaves of all cultivars by 7.2 days or $29.5 \%$ compared to those of intact stems (Fig. 2 b). Exceptions were for 'WX73', 'WX35' and 'Dancing Queen', where the removal of leaves in DI water did not significantly $(p<0.05)$
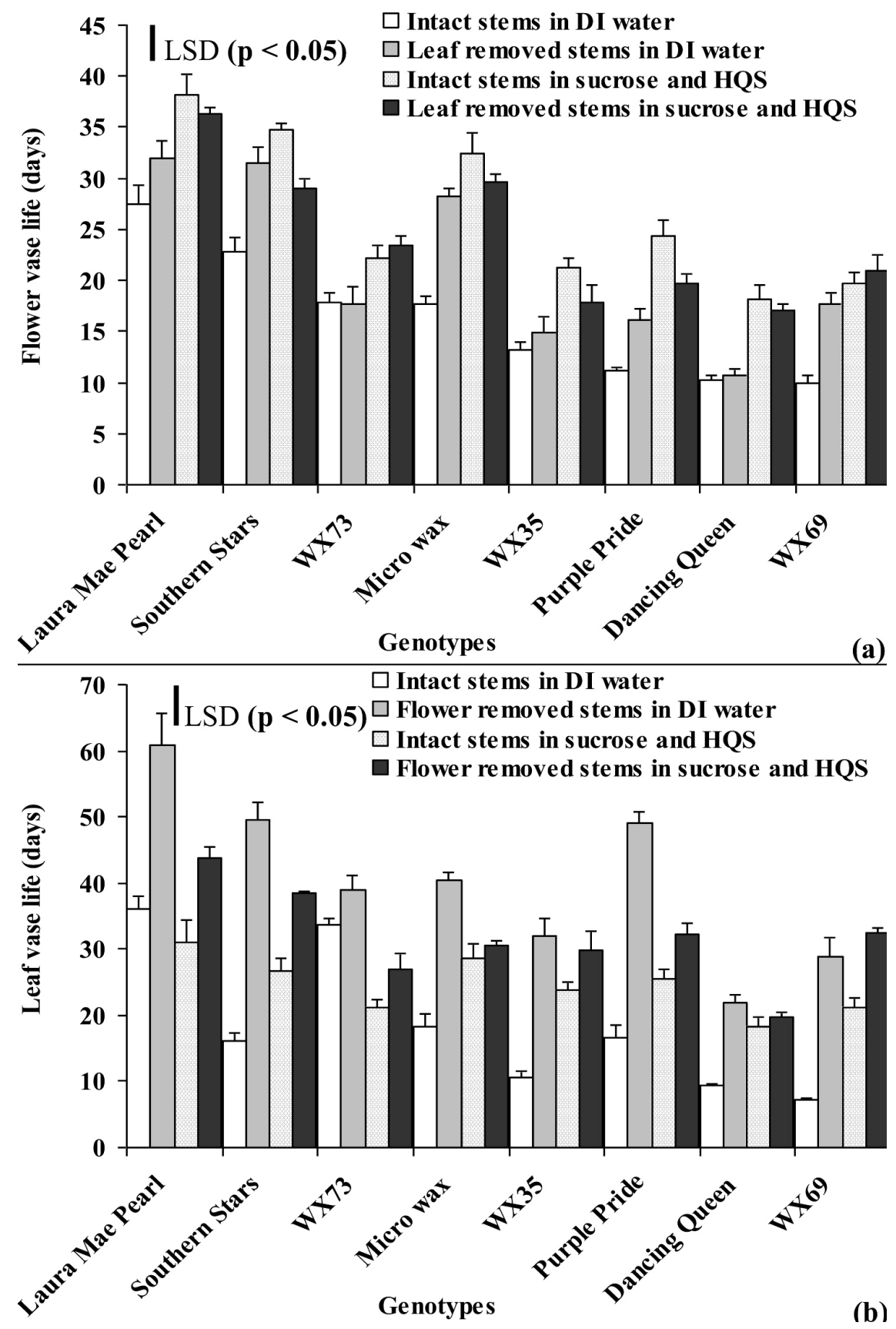

Figure 2. Vase life of flowers (a) and leaves (b) of leaf or flower removed stems, respectively, and of intact stems of cultivars in DI water and in $29.2 \mathrm{mmol}$ sucrose and $100 \mathrm{mg} \mathrm{L}^{-1} \mathrm{HQS}$. Vertical bars are standard error of means as shown. LSD at $p<0.05$ by 1 -way analysis of variation 


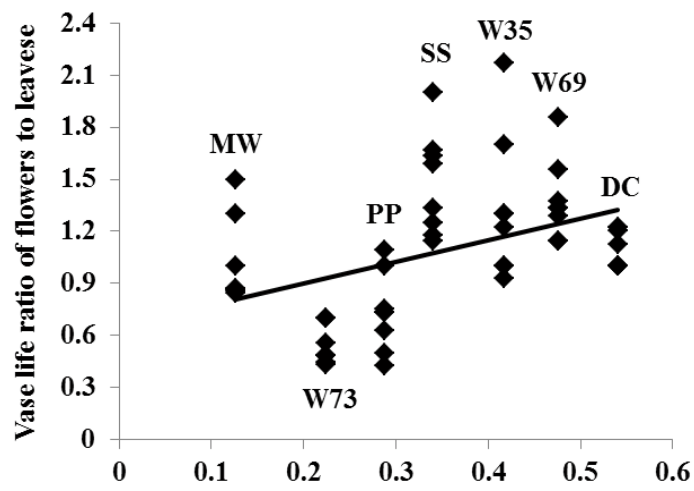

(a)

Weight ratio of flowers to stems

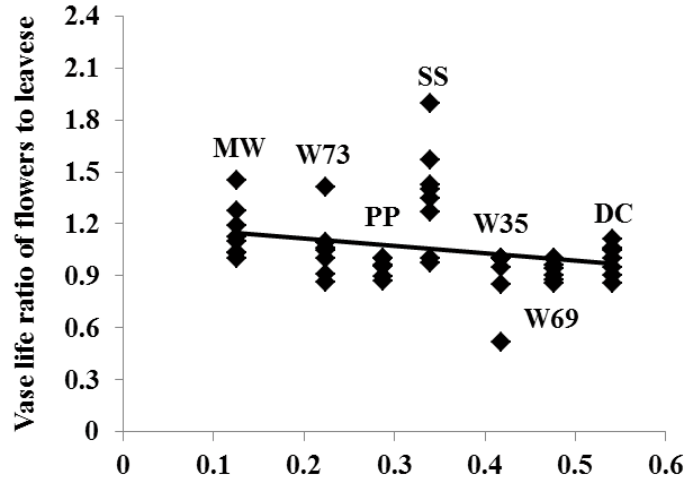

(b) Weight ratio of flowers to stems

Figure 3. Regression relationships between flowers to leaves vase life ratio and flower weight ratio of cultivars of Micro wax (MW), WX73 (W73), Purple Pride (PP), Southern Stars (SS), WX35 (W35), WX69 (W69) and Dancing Queen (DC) in DI water (a) and in $29.2 \mathrm{mmol}$ sucrose and $100 \mathrm{mg} \mathrm{L}^{-1} \mathrm{HQS}$ (b), $\mathrm{n}=56$

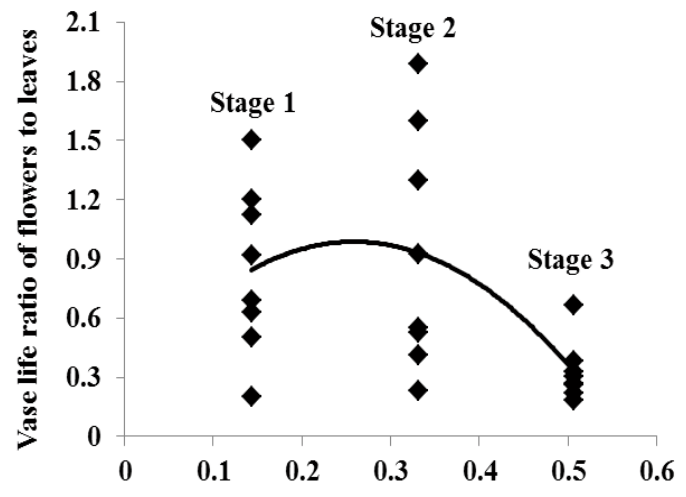

(a)

Weight ratio of flowers to stems

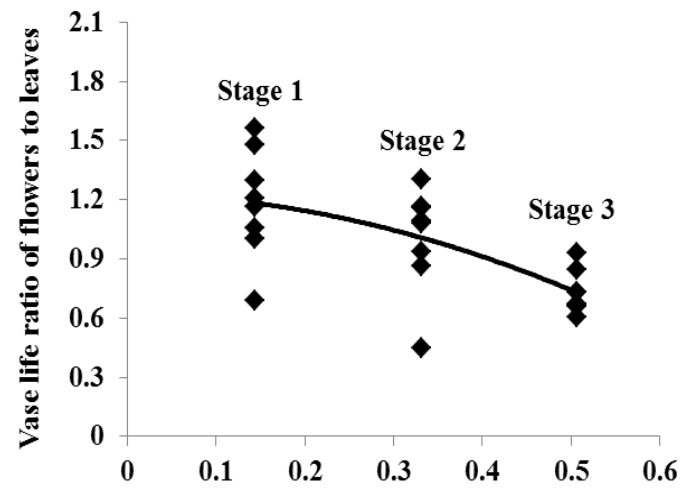

(b)

Weight ratio of flowers to stems

Figure 4. Regression relationships between flower weight ratio and flower to leaf vase life ratio of 'WX87' at different developmental stages in DI water (a) and in $29.2 \mathrm{mmol}$ sucrose and $100 \mathrm{mg} \mathrm{L}^{-1} \mathrm{HQS}$ (b), $\mathrm{n}=24$

increase vase life compared to that of intact stems (Fig. 2 a).

\section{Relationships between flower to leaf vase life ratio and flower weight ratio of seven cultivars}

Cultivars with a greater proportion of their weight in flowers compared to leaves resulted in a higher flower to leaf vase life ratio in DI water. The positive correlation between flower to leaf vase life ratio and weight ratio of flowers to stems was determined as: $\mathrm{y}=1.2532 \mathrm{x}+0.6478, r^{2}=0.177(p<0.05, \mathrm{n}=56)$ (Fig. 3 a). For flowers in sucrose and HQS, cultivars with a higher flower weight ratio had a lower flower to leaf vase life ratio. The correlation between flower to leaf vase life ratio and the weight ratio of flowers to stems was determined as: $\mathrm{y}=-0.4242 \mathrm{x}$ $+1.2002, r^{2}=0.0743(p<0.05, \mathrm{n}=56)($ Fig. 3 b).

\section{Relationships between flower to leaf vase life ratio and flower weight ratio of ' $W X 87$ '}

The flower to leaf vase life ratio of 'WX87' in DI water increased as flowers opened up to $50 \%$ then decreased with the increasing weight ratio of flowers to stems up to $100 \%$ open determined as: $y$ $=-0.10703 \mathrm{x}^{2}+5.5317 \mathrm{x}+0.2725, r^{2}=0.2996(p<$ $0.05, \mathrm{n}=24$ ) (Fig. 4 a) while the flower to leaf vase life ratio in sucrose and HQS tended to decrease with the increasing weight ratio of flowers and buds to stem determined as: $\mathrm{y}=-1.796 \mathrm{x}^{2}-0.0807 \mathrm{x}+$ 1.12317, $r^{2}=0.4309(p<0.05, \mathrm{n}=24)($ Fig. 4 b).

\section{DISCUSSION}

Competing demand between flowers and stems appeared to be controlling the vase life of flowers and leaves in waxflowers. Under conditions of 
no added sugar, the vase life of flowers increased when leaves were removed, indicating that leaves competed with flowers for endogenous and water. In the presence of sugar, the effect of the removal of leaves on the vase life of flowers was less or nonexistent. The response of the vase life of leaves to the loss of flowers was much greater than the response of the vase life of flowers to the loss of leaves while in sugar; there was not much gain in the vase life of leaves with the removal of flowers compared to that in DI water. This indicated that waxflower leaves are less competitive than its flowers for water and particularly carbohydrates and flowers are a much stronger sink for carbohydrates than leaves as in Protea neriifolia, where carbohydrate depletion in leaves resulted in leaf blackening (Dail and Paull 1995). These findings support the theory that leaves are considered a supporter providing carbohydrates for the development of flower buds (Marissen and La Brijn 1995), but may compete for water as found for Grevillea 'Crimson Yu-lo', where the removal of leaves increased the vase life of flowers (He et al. 2006). The lack of response in the vase life of flowers between the removed leaves and the intact stems of 'WX73' may have been affected by physical injury producing endogenous ethylene and causing flower drop (Joyce 1993) and shortening the vase life of waxflowers (Seaton pers. comm.). Observation during vase life assessment (data not shown) showed that the flower drop rate increased with the leaf removed stems of 'WX73' compared to other cultivars, negating gains in the flower vase life of cultivars having leaves as a source of carbohydrates. Alternatively, the 'Dancing Queen' and 'WX35' had a flower weight higher than that of the leaves. Therefore, leaf removal may not have had a significant effect on the vase life of flowers; whereas, the removal of flowers notably increased the vase life of leaves.

Sucrose provided carbohydrates for flowers (Pun and Ichimura 2003) and improved water uptake (Bravdo et al. 1974), and HQS reduced the growth of bacterial and xylem occlusion and increased water uptake, resulting in an increase in vase life of cut snapdragon (Asrar 2012). The difference in the vase life response of Geraldton wax cultivars with higher flower weight ratios suggests a large flower sink compared to leaves and thereby the gained sugars and water improved vase life.

During stages of flower opening (development), the sink and source balance changes allowed the open flowers to gain more sugars from the leaves, improving vase life. This agrees with findings of leaf blackening in Proteas, where carbohydrate depletion by flowers increased with increasing flower open stages (Dail and Paull 1995). However, as the flowers become fully open when they aged, the possible breakdown of cellular membranes may have reduced the size of the sink.

\section{CONCLUSIONS}

1. Flowers were highly competitive with leaves for water and carbohydrates.

2. Changes in the vase life of flowers and leaves were caused by changes in the weight ratio of flowers to stem, depending on genotype. Cultivars with a higher weight ratio had greater gains in flower vase life than cultivars with a lower weight ratio.

3. The vase life of the flowers of the cultivars maximized when flowers opened up to $50 \%$.

\section{ACKNOWLEDGEMENT}

Technical support from Mr. George and Mr. Kris (DAFWA) in collecting samples was acknowledged.

\section{FUNDING}

This work was funded by the Australian Government Overseas Aid Program (AusAID) in 2011 and the support of the Department of Agriculture and Food Western Australia (DAFWA) for its facilities.

\section{AUTHOR CONTRIBUTIONS}

All authors contributed extensively to the work presented in this paper. C.D.D. - conducted the research work, collected and analysed data and wrote the research work; K.S. - designed the experiments, provided the samples, gave suggestions and corrected the manuscript; Z.S. gave suggestions and corrected the manuscript.

\section{CONFLICT OF INTEREST}

Authors declare no conflict of interest.

\section{REFERENCES}

AsRar A.W.A., 2012. Effects of some preservative solutions on vase life and keeping quality of snapdragon (Antirrhinum majus L.) cut flowers. J. Saudi Soc. Agric. Sci. 11: 29-35.

Bravdo B., Mayak S., Gravrieli Y., 1974. Sucrose and water uptake from concentrated sucrose solutions by gladiolus shoots and the effect of these treatments on floret life. Can. J. Bot. 52: 1271-1281. 
Carpenter W.J., Rasmussen H.P., 1974. The role of flower and leaves in cut flower water uptake. Sci. Hort. 2: 293-298.

Dail J., PAull R.E., 1995. Source-sink relationship and Protea postharvest leaf blackening. J. Am. Soc. Hort. Sci. 120: 475-480.

He S., Joyce D.C., Irving D.E., 2006. Competition for water between inflorescences and leaves in cut flowering stems of Grevillea 'Crimson Yul-lo'. J. Hort. Sci. Biotechnol. 81: 891-897.

JoYCE D.C., 1988. Posthavest characteristics of Geraldton wax flowers. J. Am. Soc. Hort. Sci. 113: 738-742.

Joyce D.C., 1993. Posthavest floral fall in Geraldton wax flower (Chamelaucium uncinatum Schauer). Aust. J. Exp. Agric. 33: 481-487.

Joyce D.C., Jones P.N., 1992. Water balance of the foliage of cut Geraldton waxflower. Postharvest Biol. Technol. 2: 31-39.

Marissen N., La Brijn L., 1995. Source-sink relations in cut roses during vase life. Acta Hort. 405: 81-88.

Murphy K.A., Kuhle R.A., Fischer A.M., Anterola A.M., Grimes H.D., 2005. The functional status of paraveinal mesophyll vacuoles changes in response to altered metabolic conditions in soybean leaves. Functional Plant Biol. 32: 335-344.
Paulin A., 1981. Evolution comparee des glucides dans les divers organes de la rose coupee alimentee temporairement avec une solution de glucose au de saccharose. Phisiol. Veg. 19: 59-76.

Pun U.K., Ichimura K., 2003. Role of sugars in senescence and biosynthesis of ethylene in cut flowers. Jpn. Agric. Res. Qrtl. 37: 219-244.

SEATON K., Joyce D.C., 1996. Effect of postharvest dipping in insecticides on the vase life of Geraldton waxflower. Aust. J. Exp. Agric. 36: 373-378.

Seaton K., Lee K., Tan B., 2010. Vase life and root propagation of Geraldton wax (Chamelaucium spp.) cut flowers treated with glyphosate. Hortic. Environ. Biotechnol. 51(6): 545-550.

Seaton K., Poulish N., 2010. Production of premium waxflower. Department of Agriculture and Food, Western Australia. Bull. 4778.

Turner G.W., Daniel J.C., Siau S.V., Matthew L.S., Howard D.G., LANGE B.M., 2012. Experimental sink removal induces stress responses, including shifts in amino acid and phenylpropanoid metabolism, in soybean leaves. Planta 235: 939-954.

van Doorn W.G., 1997. Water relations of cut flowers. Hortic. Rev. 18: 1-85.

Received March 9, 2016; accepted November 8, 2016 